\title{
POR UMA CRÍTICA FENOMENOLÓGICA DA IMAGEM TÉCNICA DA PUBLICIDADE: O PROBLEMA DA ATENÇÃO
}

\author{
Rodolfo Rorato Londero (Comunicação - UEL)
}

\section{RESUMO}

Uma das principais dificuldades atualmente enfrentada pela publicidade é a saturação de anúncios e a escassez da atenção do consumidor. Questionando se esse cenário de escassez é um problema ou uma consequência, este artigo pretende mostrar como a própria publicidade fomenta essa briga por atenção através de seus textos científicos. Deve-se entender, portanto, como a atenção é um conceito psicologizante criado para sustentar uma economia de consumo capitalista, o que exige uma crítica fenomenológica da imagem técnica da publicidade, ou seja, da imagem construída a partir dos textos científicos da publicidade. Busca-se assim criticar o discurso científico fundador da publicidade, além discutir a publicidade em um momento de crise e fazer os publicitários refletirem sobre as origens dos equívocos de sua prática. A metodologia baseia-se em pesquisa bibliográfica e documental, principalmente na leitura da história da atenção de Jonathan Crary, da fenomenologia da percepção de Merleau-Ponty e de manuais de publicidade da primeira metade do século XX.

Palavras-chave: Publicidade; Atenção; Fenomenologia da percepção.

Se existe uma crise da eficácia publicitária, apesar do paradoxo dos investimentos crescentes - gastou-se quase US\$ 600 bilhões em publicidade no ano de 2015 (EMARKETER, 2015) -, então ela vem sendo identificada há alguns anos como saturação de anúncios e sobre-exposição da atenção do consumidor. Em 1996, um relatório do Aspen Institue afirmou que o norte-americano médio era exposto a cerca de 3 mil mensagens publicitárias por dia (ADLER; FIRESTONE, 2002, p. 31). Como solução para o problema, o instituto apostou em uma "economia da atenção". Para os relatores da conferência do Aspen Institute, "se a atenção é a mercadoria escassa na era da informação, então uma 'economia da atenção' pode nos ajudar a compreender questões referentes à maneira de decidir como alocar nossa atenção num mundo de informações praticamente ilimitadas" (ADLER; FIRESTONE, 2002, p. 51). Em 2001, provavelmente como resposta ao problema identificado pelo Institute Aspen, Thomas Davenport e John Beck publicaram o best-seller $A$ economia da atenção, onde destacaram a dura lição aprendida com o que eles denominaram de "indústrias da atenção" (agências de marketing e publicidade, empresas de entretenimento, emissoras, etc.): "a atenção do público é restrita e de soma zero", pois "os ganhos na fatia de atenção de determinada mídia decorrem exclusivamente das perdas em outra mídia" (DAVENPORT; BECK, 2001, p. 110). Um ano depois da publicação de A economia da atenção, um nome conhecido da indústria publicitária, Hal Riney, declarou o fim do anúncio de 30 segundos, comprovando o cenário de escassez descrito pelos autores do best-seller. Nas palavras de Joe Cappo,

hoje, depois de ter assistido a centenas de milhares de comerciais em nossa vida, desenvolvemos filtros mentais que são praticamente 


\section{SEMINÁRIO DE PESQUISA EM CIÊNCIAS HUMANAS - SEPECH \\ Humanidades, Estado e desafios didático-científicos \\ Londrina, 27 a 29 de julho de 2016}

impenetráveis. Podemos ver um comercial novo e dedicar a ele um instante se tanto de atenção. Se ele for atraente, podemos estender essa atenção por mais uma ou duas olhadelas. Depois disso, o filtro mental automaticamente torna cada vez mais difícil de ser penetrado quando reconhecermos um comercial velho. Como disse Hal Riney, a propaganda ficou praticamente ineficaz (CAPPO, 2004, p. 80).

Outros nomes conhecidos da indústria publicitária também chegaram ao mesmo veredito de Riney. Em 2002, Al Ries e Laura Ries, em outro best-seller de título bastante significativo, The fall of advertising and the rise of $P R$ ("A queda da publicidade e a ascensão das relações públicas"), afirmaram que a publicidade não morreu, mas perdeu sua função comercial para as relações públicas (RIES; RIES, 2002). Um dos motivos é o que os autores chamam de "efeito papel de parede", justificando-o do seguinte modo: "Apenas porque um objeto é espaçoso não significa que as pessoas prestarão atenção nele"1 (RIES; RIES, 2002, p. 10). Ou seja, não é porque há muitos anúncios que os espectadores prestarão atenção neles. Na verdade, segundo os autores, o que ocorre é o contrário: "Como resultado do volume e da variedade, nós tendemos a discriminar todas as mensagens publicitárias. Somente quando um anúncio é atípico, nós prestamos atenção" (RIES; RIES, 2002, p. 10). Portanto, devido ao excesso de anúncios, o espectador torna-se bastante criterioso, prestando atenção somente em poucos anúncios salientes: "Em geral, a publicidade é algo que você se treina para evitar. Se você ler todos os anúncios, você não teria tempo para mais nada" (RIES; RIES, 2002, p. 10). Mesmo quando consegue atrair a atenção, evitando o "efeito papel de parede", a publicidade é como pescar sem anzol: "[As campanhas] podem ser memoráveis, podem até mesmo estar conectada com a marca na cabeça do espectador, mas elas não motivam o público a comprar a marca. Elas pescam sem um anzol" (RIES; RIES, 2002, p. 40).

Diante do cenário acima, não é de estranhar que as mais avançadas técnicas de publicidade sejam derivadas do problema da atenção, como é o caso da narrativa transmídia. Apresentado em 2006 por Henry Jenkins em Cultura da convergência, o conceito propõe uma narrativa desdobrada em várias mídias, jogando o espectador de mídia em mídia para acompanhar o desfecho da narrativa. Apesar da aparente inovação, o que realmente move a técnica é o problema da atenção, ou melhor, do impacto da publicidade: devido à proliferação de meios e veículos de comunicação, Jenkins mostra que, "nos anos 1960, um anunciante poderia alcançar 80\% das mulheres americanas com uma inserção no horário nobre das três redes de TV. Hoje, estima-se que a mesma inserção teria de passar em cem canais de TV para alcançar o mesmo número de espectadores" (JENKINS, 2009, p. 101). A narrativa transmídia busca superar o obstáculo da proliferação midiática, capturando os espectadores nos mais diversos meios e veículos.

Os exemplos de crise (e solução) da publicidade são inúmeros, sendo desnecessário continuar a citá-los para demonstrar que a escassez de atenção é um problema central. Entretanto, trata-se de um problema ou de uma consequência? Até onde a publicidade contribuiu e ainda contribui para estabelecer esse cenário de escassez? Não se pretende aqui responsabilizar a concorrência econômica para justificar a saturação de anúncios, como parece mostrar a simples relação causal entre o crescimento de anunciantes e o crescimento de anúncios. Se atualmente as

\footnotetext{
${ }^{1}$ As citações em língua estrangeira foram livremente traduzidas por nós.
} 


\section{SEMINÁRIO DE PESQUISA EM CIÊNCIAS HUMANAS - SEPECH \\ Humanidades, Estado e desafios didático-científicos \\ Londrina, 27 a 29 de julho de 2016}

consequências se mostram assim, é porque a própria publicidade fomentou essa briga por atenção através de seu discurso científico. Sendo assim, a escassez de atenção é fruto do discurso científico da publicidade que, ao longo de décadas, legitima a atenção como prioridade de sua prática. Portanto, ao invés de buscar uma solução administrativa para esse problema, este artigo pretende criticar o discurso científico fundador da publicidade, se justificando por discutir a publicidade em um momento de crise e fazer os publicitários refletirem sobre as origens dos equívocos de sua prática.

Para o propósito deste artigo, deve-se entender a publicidade como um aparelho produtor de imagens técnicas. Segundo Flusser, a imagem técnica é o resultado de texto científico aplicado: "Imagens técnicas são, portanto, produtos indiretos de textos" (FLUSSER, 2011, p. 29). Ou seja, a imagem do aparelho publicitário é uma imagem construída a partir de textos científicos. O objetivo dos textos é fornecer programas, pois o que caracteriza um aparelho é o estar programado (FLUSSER, 2011, p. 42). Poderia se pensar em vários programas do aparelho publicitário, derivados de muitos textos, mas vamos citar apenas um, diretamente ligado ao problema da atenção: a tecnocracia da sensualidade. Entendida literalmente como o governo das sensações por meio da técnica, Haug define a tecnocracia da sensualidade como

o domínio sobre as pessoas exercido em virtude de sua fascinação pelas aparências artificiais tecnicamente produzidas. Esse domínio, portanto, não aparece de imediato, mas na fascinação da forma estética. Fascinação significa apenas que essas formas estéticas arrebatam as sensações humanas. Em razão do domínio dos aspectos sensíveis, os próprios sentidos passam a dominar o indivíduo fascinado (HAUG, 1997, p. 67).

Para a publicidade, chamar a atenção é controlar os aspectos sensíveis da imagem técnica visando causar um arrebatamento, um estado onde os próprios sentidos passam a dominar o espectador fascinado. Uma vez produzido o estado de fascinação, não cabe à vontade do espectador decidir se presta atenção ou não ao anúncio; os sentidos respondem por ele.

Mas por que a publicidade precisa chamar a atenção, ou seja, por que ela precisa produzir fascinação? Em um sistema econômico onde o valor de troca antecede o valor de uso (resumindo, paga-se para depois usufruir), "o que é apenas algo, mas não parece um 'ser', não é vendável” (HAUG, 1997, p. 26-27). Sendo assim, como “o capitalismo necessita radicalmente do mundo das aparências" (HAUG, 1997, p. 70), a aparência estética invade a mercadoria, configurando-se como "o valor de uso prometido pela mercadoria" (HAUG, 1997, p. 27). Mistificando a famosa definição de Marx (2004, p. 58), a aparência estética da mercadoria mostra que a utilidade de uma coisa já não transforma essa coisa em um valor de uso, pois é preciso primeiramente prometer essa utilidade, chamar a atenção para as qualidades sensíveis da mercadoria. Sem promessa, é como se não existisse valor de uso. Contudo, sabe-se muito bem que a utilidade continua lá mesmo sem nenhuma promessa. Não é a promessa do sabor da maçã que torna a maçã saborosa. Entretanto, como mostra Türcke, a alta tecnologia transformou uma filosofia insustentável em uma verdade parcial: o Esse est percipi ("Ser é ser percebido"), do teólogo anglicano George Berkeley, ganha força em uma sociedade onde "a presença corporal produz um efeito paládio e apagado em comparação com a 


\section{SEMINÁRIO DE PESQUISA EM CIÊNCIAS HUMANAS - SEPECH \\ Humanidades, Estado e desafios didático-científicos \\ Londrina, 27 a 29 de julho de 2016}

midiática" (TÜRKE, 2010, p. 41-42). A maçã da publicidade, anunciada e percebida através da mídia, torna-se mais saborosa que a maçã "anônima".

$\mathrm{Na}$ verdade, a filosofia de Berkeley sempre pareceu uma verdade inquestionável para a publicidade. Basta lembrar o antigo modelo AIDA (Atenção-Interesse-DesejoAção), até hoje citado nos manuais de publicidade. Desenvolvido originalmente no final do século XIX, o modelo AIDA afirma que a publicidade deve sucessivamente atrair a atenção do consumidor, suscitar seu interesse por informações do produto, despertar seu desejo e, finalmente, provocar a ação de compra. O modelo AIDA é apenas a forma mais conhecida de hierarquia dos efeitos, definição referente aos diversos modelos de publicidade que compreendem os efeitos como um processo sequencial envolvendo cognição, afeição e conação (JONES, 2002, p. 235-236). Frequentemente citado como o criador do modelo AIDA, St. Elmo Lewis resumia o processo da publicidade em "três fundamentos": "Você deve atraí-los para sua proposta. Você deve mantê-los interessados. Você deve convencê-los da necessidade de agir" (LEWIS, 1908, p. 77). Mesmo nessa teorização precoce da publicidade, Lewis já reconhecia a atenção como o "maior problema na mente do anunciante": "Se nós não pudermos ganhar a atenção do leitor, é manifestamente impossível para nós interessá-lo e convencê-lo" (LEWIS, 1908, p. 95). Como parece claro, a própria noção de hierarquia dos efeitos coloca a atenção como problema central, pois o sucesso dos demais efeitos depende do sucesso do primeiro efeito.

É curioso notar que o modelo AIDA surgiu inicialmente no campo das vendas, sendo adotado pela publicidade no início do século XX, na medida em que os anúncios começavam a ser vistos como "venda impressa", ao invés de "notícias do mercado" (EGUIZÁBAL, 2010, p. 41-43). Porém, afastando-se gradativamente dos manuais de vendas, a publicidade buscou sua legitimidade no campo da psicologia, sendo a primeira disciplina a abordá-la seriamente (EGUIZÁBAL, 2010, p. 14). No início do século XX, pesquisadores como George French (1909), Harry Hollingworth (1913), Henry Adams (1926), Harry Tipper e George Hotchkiss (1914), entre outros, defendiam a pesquisa em publicidade como domínio exclusivo da psicologia. Em The psychology of advertising, por exemplo, Walter D. Scott afirma que, "como a publicidade lida com a mente humana, sua única base científica é a psicologia, que é o estudo sistemático daquelas mesmas mentes que o anunciante busca influenciar" (SCOTT, 1913, p. 2). Entretanto, o modelo originário das vendas acompanhou a publicidade nessa transição para a psicologia. Por exemplo, Tipper e Hotchkiss (1914, p. 41) apresentam o modelo AIDA quase integralmente, substituindo a última etapa por "convicção", como fez Lewis em seus três fundamentos. Hollingworth descreve um processo detalhado, porém semelhante aos demais: citando apenas o primeiro efeito, ele ocorre quando "o estímulo captura a atenção, vem à tona, se separa das outras impressões" (HOLLINGWORTH, 1913, p. 28). Ou seja, para Hollingworth, a atenção se resume à pregnância (Gestalt), cabendo ao anúncio se destacar como uma figura organizada diante de um fundo desorganizado. Por sua vez, Adams compreende esse efeito como apenas um dos muitos benefícios da atenção: para ele, a atenção torna o objeto mais claro e distinto na consciência; faz ele perdurar por mais tempo e chegar mais rápido à consciência; intensifica as sensações; ajuda a memória; e conduz prontamente à ação voluntária (ADAMS, 1926, p. 83-85). De todos os autores citados, contudo, French é o mais enfático ao afirmar que atrair é "a primeira angústia do anunciante", pois

é necessário que o anúncio atraia o olho, no instante em que o relance 


\section{SEMINÁRIO DE PESQUISA EM CIÊNCIAS HUMANAS - SEPECH \\ Humanidades, Estado e desafios didático-científicos \\ Londrina, 27 a 29 de julho de 2016}

do olhar viaja pela página impressa. O olho precisa ser aprisionado. Ele não está procurando pelo anúncio, mas o anúncio precisa atacar o olho, aprisioná-lo e obrigá-lo a enviar a mensagem para o cérebro. Se isto ocorre, o anúncio cumpriu a primeira grande lei - a atração (FRENCH, 1909, p. 158).

Temos aqui o que Virilio chama de "transmutação das representações", ou seja, a passagem da imagem estável para a imagem instável: "À emergência de formas e volumes destinados a persistir na duração de seu suporte material, sucederam-se imagens cuja única função é a da persistência retiniana" (VIRILIO, 1993, p. 19). Apesar de Virilio priorizar as imagens em fuga do cinema, o mesmo fenômeno ocorre com as imagens técnicas da publicidade, como se percebe na afirmação de French: o anúncio deve "atacar" o olho do espectador, ou seja, o anúncio somente persistirá - mesmo que momentaneamente - caso abandone o suporte material e agarre à retina do olho. Contudo, isto é apenas a metade do processo, pois o anúncio deve "atacar" o olho do espectador para, assim, transmitir sua mensagem. Eis a imagem técnica em sua melhor forma: para Flusser, "o significado das imagens técnicas se imprime de forma automática sobre suas superfícies" (FLUSSER, 2011, p. 30). Ou seja, a atenção automatiza a significação. Enquanto a contemplação das imagens estáveis permitia o surgimento de vários significados, a atenção das imagens instáveis imprime um significado automático.

Não por acaso, os pioneiros citados acima (Adams, French, Hollingworth, Tipper e Hotchkiss) formam o que Colón Zayas denomina de "cânone publicitário", pois suas ideias contribuíram para o desenvolvimento do conceito atual de publicidade (COLÓN ZAYAS, 2001, p. 12). Isto justifica a legitimidade do modelo AIDA e, consequentemente, da primazia da atenção. $\mathrm{Na}$ verdade, apesar das diversas críticas (BARRY; HOWARD, 1999; JONES, 2002; HEATH; FELDWICK, 2008), a aceitação do modelo é tão grande que muitos profissionais tomam a prioridade da atenção como um consenso: "Por ser objeto de consenso que a propaganda não funciona a não ser que alguém preste atenção a ela, as agências de propaganda e os profissionais de marketing orientados para a propaganda há muito tentam conquistar, reter e medir a atenção" (DAVENPORT; BECK, 2001, p. 127). Do mesmo modo, percebe-se como grande parte da pesquisa publicitária continua a se orientar por ideias do início do século XX: citando um exemplo atual, o The Advertising Research Handbook afirma que a atenção é a "melhor medida de intrusão e ruptura, recompensando performances interessantes, envolventes e únicas" (YOUNG, 2008, p. 67).

Pode-se dizer que o modelo AIDA apenas enfatiza o que Crary (2013) reconhece como um dos grandes problemas da modernidade: a atenção, ou melhor, a capacidade de "prestar atenção". Segundo o autor, desde o final do século XIX, "o problema da atenção permaneceu mais ou menos no centro da pesquisa empírica institucional e no coração do funcionamento de uma economia de consumo capitalista" (CRARY, 2013, p. 56). Ou seja, o problema da atenção não apenas mobilizou a então nascente psicologia científica, mas também contribuiu com "um sistema econômico emergente que demandava a atenção do sujeito num amplo leque de novas tarefas produtivas e espetaculares" (CRARY, 2013, p. 53). Na verdade, em muitos casos, o estudo da atenção se desenvolveu na psicologia científica para solucionar problemas decorrentes do consumo capitalista: "Já no limiar do século XX, o controle do consumo tornou-se igualmente importante, e abriu-se um grande campo de testes psicológicos para 


\section{SEMINÁRIO DE PESQUISA EM CIÊNCIAS HUMANAS - SEPECH \\ Humanidades, Estado e desafios didático-científicos \\ Londrina, 27 a 29 de julho de 2016}

determinação de métodos para a retenção efetiva da atenção na publicidade" (CRARY, 2013, p. 98). Essa simbiose entre uma ciência nascente e uma prática de consumo emergente é tão evidente que leva Colón Zayas a afirmar que "a publicidade foi a primeira prática discursiva da cultura burguesa em legitimar os princípios de uma psicologia científica da recepção" (COLÓN ZAYAS, 2001, p. 47).

Para compreender como a atenção é um conceito psicologizante criado para sustentar a prática da publicidade e, deste modo, entender a escassez de atenção como produto do discurso científico da publicidade, é necessária uma crítica ao conceito científico de atenção. Pode-se encontrar alguns subsídios para essa crítica na fenomenologia da percepção de Merleau-Ponty, principalmente em sua crítica aos préjuizos clássicos da psicologia. Como afirma Merleau-Ponty, a atenção "é apenas uma hipótese auxiliar que se forja para salvar o prejuízo do mundo objetivo" (MERLEAUPONTY, 2011, p. 27). Ou seja, a hipótese da atenção estabelece o mundo como único fenômeno positivo: se algo não é visto, então é porque houve falta de atenção. Deste modo, o conceito de atenção resguarda a objetividade do mundo normatizando a subjetividade do observador. Entretanto, para a fenomenologia da percepção, não se trata de atacar a objetividade do mundo, criando assim um relativismo sufocante para a verdade. Para Merleau-Ponty, "precisamos reconhecer o indeterminado como fenômeno positivo" (MERLEAU-PONTY, 2011, p. 27). Portanto, o indeterminado constitui a experiência, pois não se experimenta o que já se conhece.

$\mathrm{Na}$ verdade, ao colocar a experiência e o corpo no centro de sua filosofia, a fenomenologia da percepção também questiona a precedência da atenção. Segundo Merleau-Ponty, "o sujeito da sensação não é nem um pensador que nota uma qualidade, nem um meio inerte que seria afetado ou modificado por ela; é uma potência que conasce em um certo meio de existência ou se sincroniza com ele" (MERLEAU-PONTY, 2011, p. 285). Portanto, não se trata de um sujeito que presta atenção, mas de um sujeito que surge na medida em que seu corpo se harmoniza com o mundo observado. Segundo Merleau-Ponty, "uma excitação não é percebida quando atinge um órgão sensorial que não está 'harmonizado' com ela. A função do organismo na recepção dos estímulos é, por assim dizer, a de 'conceber' uma certa forma de excitação" (MERLEAU-PONTY, 2011, p. 114). O corpo não é alvo da excitação, mas a concebe, fazendo-a surgir para ele: "se eu quisesse traduzir exatamente a experiência perceptiva, deveria dizer que se percebe em mim e não que eu percebo" (MERLEAU-PONTY, 2011, p. 290; grifo do autor). Dizer "eu percebo" é considerar a atenção como ponto de partida quando, na verdade, ela somente ocorre quando algo já se percebe em mim, ou melhor, em meu corpo. Se a psicologia sempre representou a atenção como o foco da consciência, mas se a fenomenologia sempre representou a consciência como o reflexo da experiência, então a verdadeira atenção é a abertura da experiência, a contemplação de todos os seus pormenores. Pode-se pensar aqui na "atenção uniformemente suspensa" da terapia psicanalítica como exemplo (FREUD, 1912).

Percebe-se assim que, ao invés de priorizar a atenção como manda o modelo AIDA, os profissionais da publicidade estão em melhor caminho quando adotam as descobertas da fenomenologia da percepção. No início do século XX, Adams (1926) já realizava testes sobre a eficácia das cores, antecedendo em várias décadas a fama que a psicodinâmica encontra hoje nas agências e cursos de publicidade. Naquela época ele já dizia que "vermelho, laranja, azul e preto são as cores que mais facilmente capturam o olhar quando um número é apresentado simultaneamente" (ADAMS, 1926, p. 119). Entretanto, um criativo deveria escolher e justificar a escolha de uma cor não porque ela 


\section{SEMINÁRIO DE PESQUISA EM CIÊNCIAS HUMANAS - SEPECH \\ Humanidades, Estado e desafios didático-científicos \\ Londrina, 27 a 29 de julho de 2016}

atrai mais atenção, mas porque a cor anuncia-se "pela experiência de uma certa atitude do corpo que só convém a ela" (MERLEAU-PONTY, 2011, p. 284). Ou seja, apesar de intencional, o corpo desconhece as razões da psicodinâmica das cores. ${ }^{2}$ Muitos podem acreditar que é impossível sentir o que não se percebe, confirmando assim a precedência da atenção segundo o modelo AIDA. Contudo, caso se queira saber se é possível sentir o que que não se percebe, não pergunte à um modelo científico. Pergunte ao corpo, ele sabe a resposta.

\section{REFERÊNCIAS BIBLIOGRÁFICAS}

ADAMS, H. F. Advertising and its mental laws. New York: The MacMillan Company, 1926.

ADLER, R. P.; FIRESTONE, C. M. A conquista da atenção: a publicidade e as novas formas de comunicação. São Paulo: Nobel, 2002.

BARRY, T. E.; HOWARD, D. J. A review and critique of the hierarchy of effects in advertising. In: FITZGERALD, M.; ARNOTT, D. (eds.). Marketing Communications Classics. London: Business Press, 2000.

CAPPO, J. O futuro da propaganda. São Paulo: Cultrix, 2004.

COLÓN ZAYAS, E. Publicidad y hegemonia: matrices discursivas. Bogotá: Norma, 2001.

CRARY, J. Suspensões da percepção: atenção, espetáculo e cultura moderna. São Paulo: Cosac Naify, 2014

DAVENPORT, T. H.; BECK, J. C. A economia da atenção. Rio de Janeiro: Campus, 2001.

EGUIZÁBAL, R. Teoría de la publicidad. Madrid: Cátedra, 2010.

EMARKETER. Total Media Ad Spending Growth Slows Worldwide (2015). Disponível em: <http://www.emarketer.com/Article/Total-Media-Ad-SpendingGrowth-Slows-Worldwide/1012981>. Acesso em: 30 maio 2016.

FLUSSER, V. Filosofia da caixa preta. São Paulo: Annablume, 2011.

FRENCH, G. The art and science of advertising. Boston: Sherman, French \& Company, 1909.

\footnotetext{
${ }^{2}$ Mesmo a semiótica deve resgatar sua raiz fenomenológica caso queira reaprender o sentido das cores: "não é preciso perguntar-se como e por que o vermelho significa o esforço ou a violência, o verde o repouso e a paz, é preciso reaprender a viver essas cores como nosso corpo as vive, quer dizer, como concreções de paz ou de violência" (MERLEAU-PONTY, 2011, p. 285). Não existe um código cromático, mas um corpo que vive as cores.
} 


\section{SEMINÁRIO DE PESQUISA EM CIÊNCIAS HUMANAS - SEPECH \\ Humanidades, Estado e desafios didático-científicos \\ Londrina, 27 a 29 de julho de 2016}

FREUD, S. Recomendações aos médicos que exercem a psicanálise (1912). Disponível em: $\quad<$ http://www.freudonline.com.br/livros/volume-12/vol-xii-5-recomendacoes-aosmedicos-que-exercem-a-psicanalise-1912/>. Acesso em: 30 maio 2016.

HAUG, W. F. Crítica da estética da mercadoria. São Paulo: Editora da UNESP, 1997.

HEATH, R.; FELDWICK, P. Fifty years using the wrong model of advertising. Internacional Journal of Market Research, v. 50, n. 1, p. 29-59, 2008.

HOLLINGWORTH, H. Advertising and selling: principles of appeal and response. New York: D. Appleton and Company, 1913.

JENKINS, H. Cultura da convergência. São Paulo: Aleph, 2009.

JONES, J. P. Hierarquias dos efeitos - Teorias da publicidade. In: JONES, J. P. (org.). A publicidade como negócio. São Paulo: Nobel, 2002.

LEWIS, E. St. E. Financial Advertising. Indianapolis: Levey Bros. \& Company, 1908.

MARX, K. O Capital: crítica da economia política: livro I. Rio de Janeiro: Civilização Brasileira, 2004.

MERLEAU-PONTY, M. Fenomenologia da percepção. São Paulo: Martins Fontes, 2011.

RIES, A.; RIES, L. The fall of advertising and the rise of PR. New York: HarperBusiness, 2002.

SCOTT, W. D. The psychology of advertising. Boston: Small, Maynard \& Company, 1913.

TIPPER, H.; HOTCHKISS, G. B. Advertising. New York: Alexander Hamilton Institute, 1914.

TÜRKE, C. Sociedade excitada: filosofia da sensação. Campinas: Editora da Unicamp, 2010 .

VIRILIO, P. O espaço crítico. Rio de Janeiro: Ed. 34, 1993.

YOUNG, C. E. The advertising research handbook. Seattle: Ideas in Flight, 2008. 